\title{
A imagem de Camões como espelho de Casimiro de Abreu Machado de Assis: romantismo em Camões e o jau e universalismo em Tu, só tu, puro amor
}

Adriano Lima Drummond 1

RESUMO: Neste artigo, analisamos Camões e o jau, de Casimiro de Abreu, e Tu, só tu, puro amor, de Machado de Assis. Nessas duas peças, que tem o poeta d'Os Lusíadas como protagonista, observa-se que ele repercute a concepção literária de seu respectivo autor.

ABSTRACT: This article analyses the pieces Camões e o jau by Casimiro de Abreu Tu, só tu, puro amor by Machado de Assis. In these two pieces one observes that the character Camões reflects the literary conception of its respective author.

PALAVRAS-CHAVE: Camões; romantismo; universalismo; Machado de Assis; Casimiro de Abreu.

KEYWORDS: Camões; romanticism; universalism; Machado de Assis; Casimiro de Abreu.

Camões parece marcar todo o percurso da literatura brasileira. O livro de Gilberto Mendonça Teles, Camões e a poesia brasileira, fruto do desenvolvimento de um ensaio premiado em concurso comemorativo do quarto centenário de publicação d'Os Lusíadas, e o ensaio Camões e a literatura brasileira, com o qual Hamilton Elia também participou do mesmo concurso, dimensionam a multifacetada presença do poeta quinhentista português em nossa produção literária. Já Alceu Amoroso Lima havia observado: “O maior poeta da língua portuguesa deixou reflexos do seu gênio em todas as nossas escolas literárias, do Classicismo de um Bento Teixeira ao Modernismo de um Augusto Frederico Schmidt, da geração de 1930, ou de um Geir Campos, da de 1945" (LIMA, 1959, p.23). Essa observação de Amoroso Lima, aliás, constitui ponto de partida para o rastreamento da presença camoniana na literatura brasileira tanto no livro de Teles quanto no ensaio de Elia, autores interessados, sobretudo, na ressonância da obra de Camões - seja sob o regime da estética clássica, sua parte épica e

1 Doutorando; título da pesquisa: "Camões aquém e além mar: que fizeram Teófilo Braga e Joaquim Nabuco com esse poeta?" 
lírica tomadas, em imitatio, como modelo para poemas épicos; seja na reverência inaugurada pelo romantismo ao gênio, essa mesma obra vista como fonte de diálogos textuais de grande força expressiva. Mas o homem Camões, ou sua biografia, também despertou a imaginação criadora dos escritores brasileiros, tornando-se, na segunda metade do século XIX, personagem de duas peças destacáveis: Camões e o Jau, de Casimiro de Abreu, e Tu só, tu, puro amor, de Machado de Assis.

Neste artigo, analisaremos comparativamente essas obras, no intuito de compreender como Camões serviu para expressar as concepções e os anseios literários de seus respectivos autores.

Embora Casimiro de Abreu e Machado de Assis tenham a coincidência biográfica do nascimento no mesmo ano de 1839, Camões e o jau e Tu, só tu, puro amor não são apenas produtos de dois autores bastante distintos, em termos de percurso e qualidade literários, mas também de dois autores em momentos muito diferentes em suas respectivas carreiras de escritores. Quando escreve Camões e o jau, estudante em Coimbra de Comércio, cumprindo a contragosto a vontade paterna, Casimiro é um jovem estreante autor (conta 17 anos), conforme noticia no prólogo da obra: trata-se da "primeira composição minha, ao menos a primeira que passou da pasta dos meus acanhados ensaios ao domínio da crítica" (ABREU, s.d, p. 26). A peça estreou a 18 de janeiro de 1856, em Lisboa. Mais de duas décadas depois, em 1880, por ocasião do tricentenário de morte de Luís Vaz de Camões, o Real Gabinete Português de Leitura do Rio de Janeiro encomenda, como parte das comemorações da data, a Machado de Assis uma peça, que veio a ser o Tu, só tu, puro amor. Nesse momento, Machado está prestes a publicar em volume seu romance de guinada literária, as Memórias póstumas de Brás Cubas, sendo, portanto, a essa altura um autor conhecido e reverenciado, principalmente por suas qualidades de poeta, romancista, cronista e crítico.

Casimiro de Abreu e Machado de Assis escolheram momentos distintos da vida de Camões (ou, pelo menos, do que divulgavam dela as biografias) para construírem suas peças: o primeiro toma a ação em 1578, quando o rei D. 
Sebastião e seu exército se preparam para embarcar rumo à África, onde travarão a célebre batalha de Alcácer Quibir, com os conhecidos resultados políticos e, sobretudo, econômicos catastróficos para Portugal; já o futuro autor de Quincas Borba põe em cena um Camões no tempo que antecede seu desterro da corte lisboeta, em decorrência da denúncia ao rei do caso amoroso do poeta com D. Catarina de Ataíde. Para efeitos de uma análise mais clara, tratemos das duas peças separadamente, antes de compará-las e de extrair nossas conclusões.

No prólogo de Camões e o jau, Casimiro de Abreu encontra oportunidade para desabafar as saudades da pátria e da família, sentidas desde quando, por volta de dois anos antes, partira do Rio de Janeiro no vapor Olinda rumo à Europa: “Eu chorava deveras como hoje suspiro saudoso, porque era a pátria que eu deixava; a terra onde nasci; porque lá ficaram meu pai e minha mãe, meus irmãos, tudo que de mais caro tinha no mundo!" (ABREU, s.d, p. 25). Em lamentação que se estrutura conforme a gramática gonçalvina do ufanismo, mesma referência poética para poemas líricos publicados futuramente, Casimiro de Abreu coteja o país onde estuda e o país onde nasceu:

Era este Portugal velho e caduco que hoje dorme um sono longo à sombra dos louros que ganhou outrora; era este Portugal que ainda repercute o tinir das armaduras e das espadas de seus guerreiros extintos; era este Portugal que ainda repete as doces harmonias exaladas de tantas liras sonoras; era este Portugal, pátria de meus avós, mas não minha pátria. Aqui fala-se a mesma língua que se fala no Brasil; aqui também há sol, há lua, há aves, há rios, há flores, há céu... mas o sol da minha terra é mais ardente, a lua mais suave, o canto das aves é mais terno, os rios são mais soberbos, as flores têm mais perfumes, o céu tem mais poesia. (ABREU, s.d, p. 25)

Adiante, duas imagens mais do que convenientes servem ao autor para legitimar as razões de sua dor romântica e brasileira de exilado: o índio e as plantas típicas dos trópicos - estes os mais emblemáticos pontos de apoio da afirmação literária nacional, com os quais, retoricamente (e emocionalmente), o 
poeta se identifica e se opõe à Europa, na sua civilização e na sua natureza. Diz ele:

\begin{abstract}
Não há que valha a terra natal. Tirai o índio do seu ninho e apresentai-o d'improviso em Paris: será por um momento fascinado diante dessas ruas, dessas praças, desses templos, desses mármores; mas depois falam-lhe ao coração as lembranças da pátria, e trocará, de bom grado, ruas, praças, templos, mármores, pelos campos da sua terra, pela sua choupana na encosta do monte, pelos murmúrios da floresta, pelo correr dos seus rios. Arrancai a planta dos climas tropicais e plantai-a na Europa: ela tentará reverdecer, mas cedo pende e murcha, porque lhe falta o ar natal, o ar que lhe dá vida e vigor. Como o índio, prefiro a Portugal e ao mundo inteiro o meu Brasil, rico, majestoso, poético, sublime. Como a planta dos trópicos, os climas da Europa enfezam-me a existência, que sinto fugir no meio dos tormentos da saudade. (ABREU, s.d, p. 25-26)
\end{abstract}

Essas informações ou confissões têm relevância para compreendermos melhor a construção casimiriana do personagem Camões.

Na peça, com efeito muito curta, quase não há ação propriamente dita. $\mathrm{O}$ cenário é um quarto pobre, onde repousam sobre a cama papéis amontoados. $\mathrm{O}$ poeta quinhentista, já em cena aquando da abertura das cortinas, velho e triste, ouve toques marciais vindos do rio Tejo, que lhe instigam palavras inflamadas de amor patriótico e de outros amores:

Trombeta do combate; quando soas,

Bater tu fazes com dobrada força,

Com fogo etéreo coração ardente

Que em peito português livre palpita.

(Com entusiasmo)

Meu Portugal tão belo e tão valente!

Torrão formoso, terra de magia,

Ricos sonhos do poeta, meus amores!

Sim, meus amores, porque os tive outrora...

Cala-te, coração... já não existem! (ABREU, s.d, p. 27) 
Em seguida, o protagonista se recorda, num timbre mais melancólico, do "exílio amargo" de "tantos anos... tantos!" (ABREU, s.d, p. 28), pouco antes da entrada em cena de Antônio, o fidelíssimo, bondoso, compassivo escravo javanês, "que os grilhões contente beija" (ABREU, s.d, p. 28) e sai, no mais das vezes, sem sucesso, a pedir esmolas em favor de seu senhor. Antônio, o jau, será o único interlocutor a quem Camões se dirige - sem respeito a convenções sociais como amigo. O poeta quinhentista, segundo Casimiro de Abreu, vai apresentando outros traços de sua personalidade e de seu estado físico e emocional: resignação, fé em Deus, palidez, pressentimento da proximidade da morte, nostalgia de um amor desafortunado sentido por Natércia (nome poético e anagrama de Catarina). As convenções sociais, que Camões desrespeita chamando de amigo o jau, são as que lhe foram outrora obstáculo para casar-se com sua amada, conforme confessa o personagem:

Mas o pobre Camões não tinha um nome, Não podia of'recer-lhe a mão de esposo!

Ai, loucos! Porventura, um sentimento Quereis moldá-lo a conveniências fúteis?

Quem é que ao coração jamais deu regras? (ABREU, s.d, p. 31)

Na confissão do protagonista, não se esclarece bem o motivo de sua partida no passado para o Oriente. Simplesmente em busca de glória, máscara de uma fuga, dada a impossibilidade de seu casamento com Natércia? De todo modo, trata-se, na peça, de um exílio voluntário, não uma expatriação punitiva decretada pela justiça do reino, como ocorreu segundo relatos de historiadores e biógrafos. Ainda que voluntário o exílio, num período no qual “Tudo ali respirava só tristeza" (ABREU, s.d, p. 32), o personagem diz ter sentido bastante a distância de sua pátria, bem como a de sua amada, chegando a sonhar com a morte dela.

Antônio compartilha com Camões esse patriotismo - “Eu amo muito / A terra onde nasci, a minha Java" (ABREU, s.d, p. 30) - e lembranças de um amor 
por mulher, pela qual, morta precocemente, "a dor pungente e amarga / Até à morte sentirei nesta alma" (ABREU, s.d, p. 31). Após seu senhor noticiar-lhe as desventuras do passado, o Jau, à parte, proclama indignado contra o desdém de um reino pelo "maior vate deste mundo" (ABREU, s.d, p. 33), enfermo, miserável, e finaliza suas palavras profetizando a punição divina dessa injustiça:

Filhos de Portugal, ó portugueses!

Viveis entregues aos festins malditos

Sem vos lembrar que na miséria triste

Enfermo geme, moribundo quase,

Um português também, um vate ilustre?

Ah! Sois malvados corações de pedra!

Sim, sois malvados! O perdão do poeta,

De certo o tendes, porque é bom, perdoa;

Mas dos séc'los futuros, com justiça,

Anátema tereis e fulminante,

Da infâmia o ferrete desprezível,

E a voz de Deus vos bradará severa:

"Assassinos, assassinaste [sic] o vate!"

(Ouvem-se salvas repetidas, ao longe) (ABREU, s.d, p. 33-34)

Nesse momento, Camões, perguntando ao jau o porquê do "sinal festivo [que] o canhão troa" (ABREU, s.d, p. 34), vem a saber da empresa militar de el-rei D. Sebastião: o tempo da peça situa-se em 1578, no dia em que o monarca segue com seu exército em direção à África para travar a batalha de Alcácer Quibir, cujo desfecho - já sabemos - será a derrota dos portugueses e cujas consequências, dali a dois anos, a União Ibérica. Camões, referido por Antônio como "vate", justificará a atribuição do termo, em todo o rigor semântico, ao vaticinar os desastrosos acontecimentos sucedidos nos areais africanos:

Que luz celeste me esclarece agora?

Que sombras estas que vagueiam tristes,

Que se deslizam silenciosas, quietas,

Fantasmas negros na mudez da noite?!...

Que campo é esse que se alaga em sangue, 
Teatro horrível onde impera a morte?!... Oh d'Alcácer-Quivir [sic] plaga maldita, Que presencias num só dia a queda Da nação entre todas a mais nobre! Ah! Vergonha pras armas portuguesas! [...]

Calcada está de Portugal a c'roa, Nosso pendão caiu... quebra-se o cetro...

E Dom Sebastião ousado e jovem

Ei-lo que tomba do ginete altivo

Com vida ainda, pra não mais erguer-se!

[...]

Mas que ouço?! Estes cânticos selvagens...

Este alarido e gritos de vitória...

De triunfo infeliz os solta um povo!

As mauras meias-luas já tremulam

Dos cristãos sobre as tendas tão vaidosas;

[...]

A glória e o nome português morreram!

E este tinir de ferros?! São algemas,

São grilhões que nos vem lançar Castela!!

Termos de suportar estranho jugo..

Sofrer da escravidão a morte lenta... (ABREU, s.d, p. 35-36)

Tomado de tal angústia pelo futuro próximo de Portugal, golpeado em seus sentimentos patrióticos - "nesta alma / Era o afeto maior que ora existia" (ABREU, s.d, p. 36) -, Camões profere: “Se a pátria é morta, hei-de morrer com ela" (ABREU, s.d, p. 36), logo lançando ao fogo alguns manuscritos e depois indo buscar, para destiná-lo a mesmo fim, exemplar d'Os Lusíadas. Antônio o impede, retirando das chamas o que intitula "o mais nobre brasão dum povo inteiro" e "o laurel dum vate" (ABREU, s.d, p. 37), e, erguendo-o, enuncia as palavras finais da peça:

Se é verdade que tua pátria é morta,

Este poema lembrará ao mundo

Que houve outrora um Portugal gigante

E - Camões - fora seu cantor sublime. (ABREU, s.d, p. 37)

Críticos como José-Augusto França, em O romantismo em Portugal, e Eduardo Lourenço, em Mitologia da saudade, estão em consenso quanto ao fato 
de o poeta quinhentista português feito personagem no poema Camões, de 1825, constituir o duplo de Almeida Garrett; este um poeta, àquela altura, por razões políticas, no exílio, mas saudoso da pátria, em nome da qual defendia o liberalismo contra as estruturas tirânicas do Antigo Regime, encarnadas três anos depois pelo rei absolutista D. Miguel. Muito da força que Camões teve à época e ainda hoje parece dever-se à identificação do autor com o personagem, este o duplo daquele, que escreveu a obra no exílio, assim como o outro boa parte d'Os Lusíadas (Cf. LOURENÇO, 1999, p.59; FRANÇA, 1999, p.49). Mas observa França: “Camões não é o simples pretexto para a exibição de uma dor pessoal: em 1824, tomado como modelo existencial, ele deve garantir um conhecimento moderno da realidade humana" (FRANÇA, 1999, p.49). Vem a calhar, a esse propósito, o ensinamento de Lourenço, nas palavras do qual, "Os românticos não viajam realmente em direção ao passado, antes trazem o passado para o presente" (LOURENÇO, 1999, p.59). Em Camões e o jau parece suceder-se o mesmo. Aparentemente sem a gravidade de um motivo de ordem política (caso do poeta romântico português) ou de desajustamento social (caso do autor d'Os Lusíadas), Casimiro de Abreu sofreu as dores do exílio (ironicamente na terra dos dois primeiros exilados) por imposição do pai, que o queria para comerciante. Mas a identificação do autor com o personagem não se limita a esse dado. O Camões casimiriano é tão romântico quanto o poeta fluminense, e não só quanto aos sentimentos; também (seria isto um truísmo?) na maneira como os expressa. Com efeito, Hamilton Elia refere-se à peça como obra de "inspiração romântica, adaptada perfeitamente ao espírito romântico" (ELIA, 1973, p.37). O sonho do protagonista com Natércia não esconde sua extração ultrarromântica, muito apegada a temas mórbidos; por exemplo, o da contemplação ou visão da mulher amada morta e o profundo sofrimento disso decorrido:

Uma vez que tranqüilo adormecera, De súbito me ergui todo convulso...

Sonho horrível me havia despertado.

Sonhei-a fria, já sem vida... morta! 
Aquele corpo airoso, inanimado!

Aqueles lindos olhos já sem brilho!

Os lábios purpurinos já cerrados,

Que no entr' abrir final balbuciaram

Camões! Camões! ainda com ternura!

Vacilante os cabelos apartava

Com a trêmula mão da fronte em gelo...

Visão não era; realidade pura!

Era morta a mulher que eu tanto amava,

Morta... na flor da vida!... ele era um anjo!

Desde esse dia então morri pro mundo.

As lágrimas da dor verti-as todas.

Depois... não chorei mais, sofria mudo

[...]. (ABREU, s.d, p.32)

Para além da temática romântica ou ultrarromântica, Casimiro de Abreu também amolda algumas falas de seu personagem com base no modelo da dicção que marcou o romantismo brasileiro. Os versos seguintes decerto nos recordam de imediato as canções do exílio de Gonçalves Dias e do próprio Casimiro, com seus “Ai, que saudades!", seus sabiás e tutti quanti:

Que saudades que eu tinha desta terra,

Destas veigas risonhas, destas fontes,

Destas flores mimosas, destes ares!

Nunca naquelas regiões tristonhas

O riso do prazer me veio aos lábios.

[...]

Lá não trinava o rouxinol gorjeios

Na balseira virente em noite bela,

Quando a lua prateada se retrata

Sobre as águas do lago sossegado;

Lá não ouvia a gemebunda rola

Gemer saudosa... que entristece tanto! (ABREU, s.d, 31)

Assim, o patriotismo do personagem parece também expressar o patriotismo do autor, afirmado e fundamentado no prólogo da peça. Mas não haveria aqui um conflito de "minha-pátria-é-mais-que-a-sua", sendo um português e outro brasileiro? Notemos a subjetividade da argumentação do prólogo: o Brasil só é 
"mais" do que Portugal, a Europa ou qualquer outra parte do mundo porque é nesse país que o poeta nasceu; um português ou outro qualquer estrangeiro, em consonância com o ethos romântico tupiniquim, deveria ter a sua respectiva terra como a melhor. Esse mesmo ethos - na obra de Casimiro de Abreu, expressão de uma preferência por "temas relativamente mais comuns da psicologia humana", tratados “com menor amplitude" (CANDIDO, 2000, p.179) - conduz o autor a espelhar Antônio em Camões: um e outro bondosos, patriotas, saudosos de suas amadas mortas ainda na juventude.

Na opera omnia machadiana, as referências, os vestígios camonianos são numerosos (cf. ELIA, 1973, p.39-41), alguns supostamente mais discretos, como em O Almada (cf. TELES, 1976, p.150; 203 e 261). Como dissemos acima, a peça Tu, só tu, puro amor é uma encomenda do Real Gabinete Português de Leitura do Rio de Janeiro ao escritor carioca, por ocasião do terceiro centenário de morte de Luís Vaz de Camões.

Publicou-se a obra em 1881, mesmo ano de Memórias póstumas de Brás Cubas, o romance que marca a guinada do percurso literário machadiano.

As dramatis personae da comédia (de 17 cenas) são Camões, D. Antônio de Lima, Caminha, D. Manoel de Portugal, D. Catarina de Ataíde e D. Francisca de Aragão. A primeira cena expõe a intriga palaciana que envolve o duplamente invejoso Caminha e Camões, alvo e vítima dessa inveja tanto pelo estro literário quanto por ser amado por D. Catarina. A ação da peça principia em torno de um epigrama escrito pelo protagonista, a respeito de evento bastante prosaico: em vez de uma galinha prometida, o duque de Aveiro envia ao poeta um assado. Em nota à edição de 1910 da coletânea de seu teatro, Machado de Assis, a propósito, defende-se de uma correção histórica de Teófilo Braga, quem acusara a impossibilidade do episódio, uma vez que em 1553 - tempo diegético da peça - não tivera sido ainda concedido à pessoa o título de 'duque de Aveiro'; isso só viria a ocorrer quatro anos depois. Diplomaticamente, Machado resolve a querela: 
Temos ambos razão, o Sr. Teófilo Braga e eu. Com efeito, o ducado de Aveiro só foi criado formalmente em 1557, mas o agraciado usava o título desde muito antes, por mercê de D. João III; é o que confirma a própria carta régia de 30 de Agosto daquele ano, textualmente inserta na Hist. Geneal. de D. Antônio Caetano de Souza, que cita em abono da asserção o testemunho de Andrade, na Crônica d'El-Rei D. João III. Naquela mesma obra se lê (liv. IV, cap. V) que em 1551, na trasladação dos ossos d'elrei D. Manoel, estivera presente o duque de Aveiro. Não é, pois, impossível que a anedota ocorresse antes da primeira ausência de Camões. (ASSIS, 1938, p.265)

Seja como for, voltemos ao enredo da comédia. Caminha nunca perde oportunidade para desmerecer a grandeza da poesia daquele "bem-amado entre os últimos de Coimbra" (ASSIS, 1938, p.288), "um magro poeta de camarins" (ASSIS, 1938, p.295), um "rufião, a quem vadios deram foros de letrado" (ASSIS, 1938, p.295) e que até poderia tornar-se um admirável vate, caso se dedicasse "Com boa vontade, mais esforço, menos soberba, gastando as noites, não a folgar pelas locandas de Lisboa, mas a meditar os poetas italianos" (ASSIS, 1938, p.268). Todavia, a Caminha mais incomoda o amor que D. Catarina de Ataíde - contra vontade do pai, D. Antônio de Lima - vota a Camões. Vingativamente interessado na publicação desse relacionamento proibido, que, ao fim, rende ao protagonista o desterro, Caminha chega a confessar a essa mulher, a quem também ama, mas sem correspondência: “[...] quereis saber o que me fez o vosso Camões? Não é só a sua soberba que me afronta [...]. Também não é porque ele vos ama, que eu o odeio; mas vós, senhora D. Catarina de Ataíde, vós o amais... eis o crime de Camões. Entendeis?" (ASSIS, 1938, p.294). Adiante, com todo o ódio de um amante desprezado, ameaçando revelar a D. Antônio o caso entre sua interlocutora e o protagonista, diz: "A vossa angústia será a minha consolação. Onde falecerdes de pura saudade, aí me glorificarei eu. Chamai-me agora perverso, se o quereis, eu respondo que vos amo... e que não tenho outra virtude" (ASSIS, 1938, p.296). Em tão delicada situação, D. Catarina acaba por personificar o romanesco conflito entre a obediência ao pai (cuja vontade representa as convenções 
sociais) e a obediência ao coração. Ela, apesar de, evasivamente, não jurar para o pai afastar-se de Camões, tanto não afronta a ordem paterna quanto não resiste a render-se ao amor, jurando enfrentar tudo e todos, em nome de seu amor. Contudo, ao contrário do poeta, que, perante o risco de serem flagrados a sós, diz "Que venham! Tomara eu que nos vissem! Bradaria a todos o meu amor, e à fé que o faria respeitar" (ASSIS, 1938, p.286), D. Catarina de Ataíde não deixa de ser, nas palavras do próprio Camões, uma "Mentirosa, eterna mentirosa!" (ASSIS, 1938, p.285), cuja firmeza não merece a confiança de quem tanto a ama. Apesar das tentativas de ajudar e "consolar os desgraçados" (ASSIS, 1938, p.302), por parte de D. Manoel de Portugal e D. Francisca de Aragão - ambos muito amigos do casal do que eles amorosamente menos afortunado -, o rei finalmente, a pedido de D. Antônio de Lima, já certo do caso entre sua filha e Camões, decreta o desterro deste. Na visão de D. Antônio, tal punição "restituiu a honra a um vassalo, e a paz a um ancião" (ASSIS, 1938, p.303), sem temor de poder, com isso, matar a filha de desgosto, pois "Amores fáceis de curar são esses que aí brotam no meio de galanteios e versos. Versos curam tudo. Só não curam a honra os versos; mas para a honra dá Deus um rei austero, e um pai inflexível..." (ASSIS, 1938, p.303-304). Suas palavras se confirmarão logo a seguir, justificando a denominação de comédia, quando o protagonista encerra a peça, na superação das dores pelo afastamento de sua amada:

E não choro, não; não choro... não quero... (Forcejando por ser alegre). Vedes? até rio! Vou-me para bem longe. Considerando bem, Ásia é melhor; lá rematou a audácia lusitana o seu edifício, lá irei escutar o rumor dos passos do nosso Vasco. E este sonho, esta quimera, esta coisa que me flameja cá dentro, quem sabe se... Vede lá, ao longe, na imensidade desses mares, nunca dantes navegados, uma figura rútila, que se debruça dos balcões da aurora, coroada de palmas indianas? É a nossa glória, é a nossa glória que alonga os olhos, como a pedir o seu esposo ocidental. E nenhum lhe vai dar o ósculo que a fecunde; nenhum filho desta terra, nenhum que empunhe a tuba da imortalidade, para dizê-la aos quatro ventos do céu... Nenhum... (Vai amortecendo a voz). Nenhum... (Pausa, fita D. 
Manoel, como se acordasse, e dá de ombros). Uma grande quimera, senhor D. Manoel. Vamos ao nosso desterro. (ASSIS, 1938, p.308)

De fato, os versos vão curar tudo, versos que se sugere serem da epopeia, do que o poeta se conta, clama por ser escrita, numa comparação bastante conveniente: Camões não esposará D. Catarina de Ataíde, mas, como "filho desta terra", Portugal; o poeta será o "esposo ocidental" da "nossa glória". Na verdade, em termos psicológicos, não há um salto brusco: primeiro, explica Machado de Assis, em sua nota: “Busquei, sim, haver-me de maneira que o poeta fosse contemporâneo de seus amores, não lhe dando feições épicas, e, por assim dizer, póstumas" (ASSIS, 1938, p.264), ou seja, não romantizando o personagem como tanto tinha feito o romantismo; segundo, o protagonista, em certa passagem, diz, cheio de mistérios, haver em sua fronte "alguma coisa mais do que simples versos de desenfado", para a qual lhe inspiraria um "sonho... Às vezes cuido cá dentro mais do que a minha vida e o meu século... Sonhos... sonhos!" (ASSIS, 1938, p.279) e, ao longo da peça, sente-se atraído pela África e pela Ásia: “[...] sinto umas tonteiras africanas. Pois que me fecham a porta dos amores, abrirei eu mesmo as da guerra. Irei lá pelejar, ou não sei se morrer... África, disse eu? Pode ser que Ásia também, ou Ásia só; o que me der na imaginação" (ASSIS, 1938, p.307). O final de Tu, só tu, puro amor é feliz, como ensinam os cômicos versos de Álvares de Azevedo, em "Namoro a cavalo": "Se ela quisesse eu acabava a história / Como toda a Comédia - em casamento..." (AZEVEDO, 2000, p.242). Na peça machadiana, o casamento se dá com a poesia, o único ("tu só") amor puro que se mantém constante no coração do poeta, que, pela superação de força épica, vislumbra a escrita de uma epopeia, inalcançável ao engenho de outros poetas portugueses da época. Assim, a resposta é 'não' à pergunta de Camões, já ciente do decreto de seu desterro: “Venceu então o Caminha? Talvez os versos dele fiquem assim melhores. Se nos vai dar uma nova Eneida, o Caminha? Pode ser, tudo pode ser..." (ASSIS, 1938, p.305). Ao vencedor, Os Lusíadas. 
Embora tenha amigos e admiradores (D. Manoel de Portugal e D. Francisca de Aragão) e até mesmo quem o ame (D. Catarina de Ataíde), Camões é socialmente, na peça, um desajustado, uma persona non grata. Sua poesia e suas relações provocam a inveja, o ódio e o desprezo dos poderosos e seu desterro parece apenas traduzir essa sua condição social problemática, além de corroborar com seu próprio anseio do longínquo, de onde pressente voltar à pátria, nas palavras de Machado de Assis em nota, "com a imortalidade nas mãos" (ASSIS, 1938, p.264). Constitui-se um antagonismo em que se firma a tensão da comédia, protagonizado por Camões, naturalmente, e por Caminha, ambos poetas. Caminha, tomado pela inveja, aparentemente sua verdadeira base de fundamentação valorativa, vê Sá de Miranda ("Poeta é o nosso Sá, o meu grande Sá!” (ASSIS, 1938, p.268)) como superior a Camões ("esse arruador, esse brigão de horas mortas" (ASSIS, 1938, p.268)). O personagem postula uma poesia que se paute no modelo da renascença italiana, modelo, aliás, divulgado em Portugal pelo 'seu grande Sá' e também marca social da corte portuguesa; diz Caminha: "Sua Alteza, cuido que continuará, e ainda em bem, algumas boas tradições de El-rei seu pai. Damas formosas, e, quanto possível, letradas. São estes, dizem, os bons costumes italianos", para logo em seguida perguntar: “E vós, senhor Camões, por que não ides à Itália?” (ASSIS, 1938, p.288). Essa ideia de imitação, literária e existencial (Caminha aconselha o protagonista: “Com que, ides à África? Lá estão os nossos em Mazagão, cometendo façanhas contra essa canalha de Mafemede; imitai-os." (ASSIS, 1938, p.291)), confronta-se com a postura de Camões, personagem que encarna a espontaneidade do gênio, inconformado com as convenções da sociedade: "Em que ordenação, em que escrito, em que bula, em que escritura, divina ou humana, foi já dada como delito amarem-se duas criaturas?" (ASSIS, 1938, p.291). Se por um lado seu gênio o prejudica socialmente (sobre o desterro decretado, o amigo D. Manoel de Portugal reflete: “A culpa - força é confessá-lo - a culpa é dele, do meu Camões, do meu impetuoso poeta; um coração sem freio..." (ASSIS, 1938, p.302); por outro lado, alçá-lo-á ao posto de maior poeta do reino. Com isso, talvez possamos enxergar certos elementos de romantização da figura de 
Camões, o que não ocorre, todavia, em contornos romanescos: o "puro amor" do poeta não é por D. Catarina de Ataíde, nem mesmo pela pátria (pontos de grande insistência no tratamento romântico ficcional ou biográfico do personagem), como disse antes, Machado de Assis atribui a devoção amorosa maior do quinhentista português à poesia, de modo que o desfecho da comédia, curiosamente, com contornos realistas, endossa as palavras - já citadas linhas acima - do pai avesso ao amor de sua filha com o protagonista: "Amores fáceis de curar são esses que aí brotam no meio de galanteios e versos".

Há de se destacar que essa comédia traça um percurso interessante, paralelo ao enredo: vamos do epigrama, com seu tema o mais prosaico (a promessa não cumprida do envio de uma galinha ao protagonista), passamos por excertos de sonetos amorosos célebres, e chegamos ao anúncio da opus magna camoniana - evolução que é a da própria consciência artística e existencial do personagem. Não obstante essa ascensão poética - do trivial epigrama à universal epopeia -, concede-se lugar a elementos baixos que dificilmente encontram espaço em obras românticas, conforme exemplificam o Camões, de Almeida Garrett, e o Camões e o Jau, de Casimiro de Abreu. Mesmo a pobreza do poeta foi passível de romantização, algo tão possível quanto a sacralização da miséria realizada pelos evangelistas.

Para fins conclusivos deste artigo, cumpre observar que, não obstante certa parcela da crítica e da historiografia literárias, assinalar postura lusófoba entre autores românticos brasileiros e mesmo distanciamento da cultura portuguesa, ambas as peças aqui analisadas apontam para uma afirmação contrária. Casimiro de Abreu, pertencente ao cânone do romantismo nacional, autor de canções de tom ufanista, enxergou na biografia e na poesia de Camões espelho onde refletir a própria imagem de poeta saudoso da terra, contestador de convenções sociais - em suma, mais do que um romântico, trata-se de um Camões romantizado à brasileira. A peça é tão simples na arquitetura dramática e superficial na constituição psicológica dos personagens quanto, via de regra, se apresentará a poesia de Casimiro de Abreu. Tu, só tu, puro amor, por sua vez, já manifesta a concepção literária machadiana de maturidade artística, que 
sorvia doses do que propunha a corrente realista e traía a anseios clássicos. Esse realismo e classicismo machadianos expressam-se, na peça, respectivamente em: 1) a defesa de que a postura com relação ao amor diferencia-se no século XVI do que se sucede no século XIX, isto é, seria historicamente inverossímil o fato de Camões ter nutrido amor perpétuo por Catarina; e 2) a imagem de um Camões supranacional, que atinge pela arte uma dimensão expressiva universal. A esse propósito, a gradação do epigrama satírico, sonetos amorosos - poema épico, apontada na peça, parece-nos estar em sintonia com a consciência machadiana de progressão poética que os títulos de seus livros e de poemas sugerem: Crisálidas, Falenas, Americanas e Ocidentais.

Quanto à peça de Machado de Assis, desconsideramos o problema, referido por Cecília Loyola, em livro sobre o teatro do escritor carioca oitocentista, tanto de "enfrentar a palavra crítica da tradição que o cristalizou como pouco afeito à cena" quanto o de "combater o costume, mais antigo ainda, de deixar as coisas como estão" (LOYOLA, 1997, p.13). Com efeito, a questão da qualidade dramática de ambas as peças - Camões e o jau e Tu, só tu, puro amor não se considerou aqui, nem para ser defendida, tampouco atacada. Importounos, sim, o objetivo de contribuir nas pesquisas sobre como o poeta d'Os Lusíadas integra o legado literário do século XIX brasileiro, em seus distintos momentos e manifestações.

\section{Referências bibliográficas}

ABREU, Casimiro. Poesias completas. Rio de Janeiro: Ediouro, [s.d.].

ASSIS, Machado de. "Tu, só tu, puro amor". In: Theatro. Rio de Janeiro; São Paulo; Porto Alegre: W. M. Jackson, 1938. pp. 263-308.

AZEVEDO, Álvares de. Obra completa. Rio de Janeiro: Nova Aguilar, 2000.

CANDIDO, Antonio. O "belo, doce e meigo": Casimiro de Abreu. In: Formação da literatura brasileira: momentos decisivos. 9a ed. Belo Horizonte: Itatiaia, 2000. vol 2. pp. 173-179.

ELIA, Hamilton. Camões e a literatura brasileira. Rio de Janeiro: MEC; UFF, 1973. 
FRANÇA, José-Augusto. O romantismo em Portugal. $3^{\text {a }}$ ed. Lisboa: Livros Horizonte, 1999.

LOURENÇO, Eduardo. “Romantismo, Camões e a saudade”. In: Mitologia da saudade. São Paulo: Companhia das Letras, 1999. pp.54-64.

LOYOLA, Cecília. Machado de Assis e o teatro das convenções. Rio de Janeiro: Uapê, 1997.

TELES, Gilberto Mendonça. Camões e a poesia brasileira. $2^{\mathrm{a}}$ ed. São Paulo; Brasília, Quíron; MEC: 1976. 